\title{
THE EFFECT OF USING OUTLINES ON IDEA DEVELOPMENT QUALITY OF STUDENTS ESSAY WRITINGS
}

\author{
Kisman Salija \\ Universitas Negeri Makassar \\ Email:kisman.salija@yahoo.com
}

\begin{abstract}
The study dealt with the entity and process of essay writings both using and without using an outline. It aimed at finding out (1) the idea development quality of two essays by using outline, (2) the idea development quality of two essays without using outline, and (3) the significant difference of idea development quality of the two essays with and without using outlining strategy. The study was experimental with factorial and repeated measure design. The results showed that using outlining strategy was significantly better than without using it, and the comparison indicated the same results as classification both with and without outlines. It was strongly recommended that the pre-writing strategy was extremely pivotal to have good idea quality development.
\end{abstract}

Key words: writing, outlines, entity, process, essay.

\section{INTRODUCTION}

Recently, the issue of essay writing has drawn a great deal of interest among scholars particularly the effect of memory span on writing strategies (Piolat \& Fruttero, 2011); modeling in essay writing (Hayes, 2011); learning to write effectively (Torrance, 2011); research writing and presentation pattern (Ayam, 2010); the effect of production activities in relation to text quality (Braaksma, Rijlaarsdam \& Bergh, 2010) and error analysis on essay writing (Darus \& Subramaniam, 2009; Leitjen et al, 2011).

The research, however, which focuses on the use of formal outlines to improve the idea development quality of essay writing, is very limited. Outlining is one of the prewritingstrategy activities which functions as a blue print from which the writing is to be based on. Writers who are accustomed to making outlines before writing find it as an effective and clear way of organizing ideas (Goose, 2001; Crème \& Lea, 2003; Davis, 2004; Donahue, 2007). It can also help writers finish writing quickly and improve grammar. To some experts, to have finished writing an outline is presumed to have written seventyfive percent of the writing and with it writing will be very smooth.

Research found that among the four language skills, writing was more complicated for the students to master in the sense that it took a long process, starting from prewriting and moving up to editing, and to require various writing skills or abilities i.e. skill to make an outline, to develop a paragraph, to write discourse that was grammatical, unified, well-organized, and coherent (Creme and Lea, 2003).

According to Sulistiyo (2008) that writing, of the four skills, was the least priority skill for the students to learn starting from lower to higher level. In addition, when writing, even in a short paragraph, they still made considerable mistakes. In writing a short essay, they usually failed to express a thesis statement of the writing that introduces the topic to be discussed and the central idea of the essay. Besides, they were also not successful in writing good topic sentences of body 
paragraphs. The topic sentences for paragraphs, for example, were very narrow in which they almost had nothing to tell or sometimes the topic sentences were too large in which they contained more than one idea (Duigu, 2003). Another identified problem the students face in writing is the inability of the students to develop effective paragraphs or essays. The supporting sentences are not entirely about the central ideas. They leave out the criteria of being unified, coherent, and well-developed and organized (Darus and Subramaniam, 2009). Illegibility of writing is influenced by several factors, and bad organization of ideas is one of them. Many readers are unsuccessful to get the ideas of printed materials, getting only parts of the writers' ideas or totally failed, because the ideas are not well organized. The flow of ideas does not run smoothly and such that the quality of writing is far from expectation.

Different writers have different strategies of writing. Outlining is one of the prewritingstrategy activities in which the materials collected are gathered or organized. It functions as a blue print from which the writing is to be based on. Writers who are accustomed to making outlines before writing find it as an effective and clear way of organizing ideas (Goose, 2001; Crème \& Lea, 2003; Davis, 2004; Donahue, 2007). It can also help writers finish writing quickly and improve grammar. Writing an outline is presumed to have written seventy-five percent of the writing and with it writing will be very smooth (Creme and Lea, 2003).

In addition to the usefulness of outlining as mentioned above, another main reason to make an outline for writing is due to the limit capability of working memory. In order to understand environment or to have perception on something, people use senses. However, not all things perceived via the senses can stay longer in the memory. Therefore, it is through formal outline can a writer express things perceived logically and systematically.
Writing strategy with outlining is more efficient and successful. It can help a writer organize his ideas and give focus on relevant materials as well as organize logical supporting details. Besides, it can make the writing run smoothly since the outline of ideas is already at hand. According to Crème and Lea (2003), it is not easy for a writer to start writing without making a framework which is called an outline. How experienced one is, he still needs an outline to follow in order to produce a qualified piece of writing - a writing containing clear and well-organized ideas and expressed in high-quality language.

This article will look at the impact of outlining and non-outlining strategy on the quality of idea development of students' essay writing.

\section{METHOD}

This study was an experimental research which has a factorial design with repeated measures. The subjects of the study were tested under two different conditions using repeatedmeasures design. Considering the research questions and relating them to the different treatments the subjects went through, this study made use of the second application or form of repeated measures (Gay, et al, 2011) that is, a subject was exposed to two different treatments. To be more precise, with these repeated measures, the same individual or person took two different measures in varied order. The data were taken from the same individual on a set of different tasks at a period of time.

This experimental study with repeated measures divided the subjects into two-half groups. The division of subjects was mainly intended for counterbalancing that is to control the order effects of giving two measures at one period of time. The grouping was not for comparing the two groups; instead, sets of composition qualities or scores of the same subjects or individuals were compared. 
The two halves of the subjects were assigned to write exposition in two methods of development: Entity and Process, once with an outline and the other without an outline. This means that each subject wrote two pairs or sets of compositions. The total of composition to write by the same individual was four.

Outline making prior to essay writing was the treatment for the experimentation, but in order to see the effects of it on dependent variable i.e. performance in writing exposition, the students were also assigned to write composition without making an outline. Both composition writing strategies, using and without using an outline, were levels or categories of the independent variable indicating strategy factor. Similarly, the two methods of exposition tagged under the variable of exposition were levels of the other independent variable indicating method factor. The writing performance or quality of the subjects was the dependent variable of the study.

The results of the two tests of the same students, when using and not using an outline, were compared to examine the effects of the manipulation of the independent variable on the dependent variable as well as to look over the interaction between the levels of the two experimental variables. The study gave no pretest to the subjects since the objective was not to compare qualities of compositions of a pretest and a posttest as in an experimental study with pre and posttest design.

The subjects of the study were 36 university students at one of the state universities in Makassar. This course preoccupied the students with knowledge of outlining writing in various methods that they needed when they did the writing tasks of the research. The target subjects were in two parallel classes consisting of eighty students. One class was taken randomly as the accessible subjects or sample and the other class was used for instrument try-out.
The instrument used to collect data was direct writing tests-expository writing tests using and not using an outline. The test consisted of directions and topics to be selected one and to be developed into a composition. It was tried out three times before it was used. The try-out of the test was administered by the researcher himself.

There are three common methods for judging student writing and assigning grades: holistic, analytic, and primary trait. These methods are different from each other in terms of writing aspects to assess. The focus of assessment of this study was on idea development, that is, how the subjects of the study developed the thesis statement into paragraphs of a composition - a particular aspect of writing to score. Therefore, the scoring method suitable to employ was Primary Trait Method.

The primary trait scoring method aimed at assessing the compositions of a subject both if using and not using an outline and the focus of the assessment was on idea development. The rubric consisted of three aspects: score, range of score and criteria. Each of the three aspects was divided into five bands with criteria or descriptors for each band, ranging from the highest to lowest.

Two raters were involved in rating students' composition. To achieve an acceptable level of inter-rater reliability, the two raters were trained. The training gave focus on the scoring rubric which outlines the criteria to be used in judging compositions. The final score of a composition was the average of two scores of the two raters.

The researcher collected the data employing counterbalanced procedure. In this procedure the single group of the subjects was divided into two halves that are called two treatment groups. The two-halves of students received treatments but the treatments were in different order: Outlining/Non-Outlining versus Non-outlining/Outlining with a specified method of exposition. The different 
order of treatments functioned to control the additional sources of invalidity.

The data of the study were composition scores. The data were analyzed by means of inferential statistics. This statistical analysis was used to answer the problem statement of the study dealing with interaction of two independent variables, significant difference between the independent variables as well as the significant difference between cells within independent variables.

The study has two independent variables to manipulate. This signals that the study weighs a factorial ANOVA design. The design involves two factors: writing strategy (Factor A) and methods of exposition (Factor B). Factor A has two levels: using an outline (A1) and not using an outline (A2); and factor B has two levels: comparison (B1) and classification (B2). This study is symbolized with a $2 \times 2$ factorial design. In this design the subject were exposed to a combination of treatments, that is, one level of one factor and one level of the other factor.

The study has three research questions:

1. Is there any significant difference on the idea development quality of the two types of student essay writings with outlining?

2. Is there any significant difference on the idea development quality of the two types of student essay writings without outlining?

3. Is there any significant difference between using an outline and without using an outline on the idea development quality of students' essay writing?

To answer the questions, the study analyzed the data using different methods. One research question needed a particular method of analysis, or a combination of methods. The total of essay writing of 36 students was 144 items.

To analyze the data relating research question 1, one way ANOVA and Turkey's test for a pair wise comparison between outlining and non-outlining were used. They were intended to find out the means of the two levels of writing strategy whether significant or insignificant. More specifically, they were applied to examine which of the two means was greater, as well as examining the mean difference between them.

To analyze the data relating to research question 2, the researcher used Turkey's tests for all pair wise comparisons among levels of strategy and levels of exposition, that is, when the students wrote compositions with outlining. For this purpose, two pairs of methods were compared. The general objective of the test is to compare the means of each paired method whether significant or insignificant, and to find out the mean difference between them.

For research question 3 , the researcher also used Turkey's tests for all pair wise comparisons among levels of strategy and levels of exposition, that is, when the students wrote compositions without outlining. For this aim, two pairs of methods were compared. The objectives of the test are to compare the means of each paired-method whether significant or insignificant, and to find out the mean difference between them.

\section{FINDINGS AND DISCUSSIONS}

This part provides the result and discussions of how the impact of the using of outline (and without outline) on the quality of students' essay writing.

\section{Essay Writing with Outlining Strategy}

The statistical analysis showed that the means of the two paired-methods compared were insignificant difference. This indicates that the performances of the students on both methods were almost the same. The evidence proved that there were no significant differences between the methods on the idea development quality of students' composition. The insignificant difference in the qualities of 
composition was due to the reality that the students have possessed adequate writing abilities or skills to write the two types of expository compositions using an outline. The ability of the students to write Entity composition was equal to their ability to write Process composition.

The table below shows significant differences between two essays with outlining strategies.

Table 1. Differences between two essays with outlining strategies

\begin{tabular}{|c|c|c|}
\hline $\begin{array}{l}\text { Writing process } \\
\text { With outline }\end{array}$ & $\begin{array}{l}\text { Means Score } \\
\text { in Entity } \\
\text { Essay }\end{array}$ & $\begin{array}{l}\text { Means } \\
\text { Score in } \\
\text { Process } \\
\text { Essay }\end{array}$ \\
\hline $\begin{array}{l}\text { Total number of } \\
\text { words }\end{array}$ & $\begin{array}{l}260(18.720 \\
\text { words) }\end{array}$ & $\begin{array}{l}258 \\
(18576 \\
\text { words })\end{array}$ \\
\hline Total sentences & $\begin{array}{l}17(1224 \\
\text { sentences) }\end{array}$ & $\begin{array}{l}16.5 \text { (1188 } \\
\text { sentences) }\end{array}$ \\
\hline $\begin{array}{l}\text { Total } \\
\text { paragraphs }\end{array}$ & $\begin{array}{l}5.5 \text { (400 } \\
\text { paragraphs) }\end{array}$ & $\begin{array}{l}5.3 \text { (385 } \\
\text { paragraphs) }\end{array}$ \\
\hline $\begin{array}{l}\text { Total essay } \\
\text { writings }\end{array}$ & 72 & 72 \\
\hline
\end{tabular}

It is shown in the data that the performances of the students in the two pairs of methods were not significantly different. Although the performances of the students were not significant difference, it was found that the students performed better on comparison method compared to classification. To sum up, the performances of the students if using an outline to write a composition with Entity method were not significantly different from Process method.

\section{Essay Writing with No Outlining Strategy}

The statistical analysis showed that the two paired methods compared showed insignificant difference in means. This indicated that the performances of the students on both methods were almost the same. This evidence showed that there were no significant differences among methods on the idea development quality of students' composition. As in the composition writing using an outline, the insignificant difference in students' performances was attributed to their equal skills in writing compositions. The students indeed have possessed identical skills to write the two types of expository compositions using no outline. The students' skills to write Entity composition was equal to their ability to write Process.

The following table below shows the mean score of idea development of the two essays without outlining strategies.

Table 2. Mean score of idea development of the two essays without outlining strategies

\begin{tabular}{lll}
\hline $\begin{array}{l}\text { Writing process } \\
\text { Without } \\
\text { outlining }\end{array}$ & $\begin{array}{l}\text { Means } \\
\text { Score in } \\
\text { Entity } \\
\text { Essay }\end{array}$ & $\begin{array}{l}\text { Means Score } \\
\text { in Process } \\
\text { Essay }\end{array}$ \\
\hline $\begin{array}{l}\text { Total number of } \\
\text { words }\end{array}$ & $\begin{array}{l}253 \\
(18.216\end{array}$ & $\begin{array}{l}\text { 251 (18072 } \\
\text { words })\end{array}$ \\
Total sentences & $15.5(1116$ & $15(1080$ \\
& $\begin{array}{l}\text { sentences }) \\
\text { sentences }) \\
\text { Total }\end{array}$ & $5(360$ \\
paragraphs & paragraphs $)$ & paragraphs $)$ \\
$\begin{array}{l}\text { Total essay } \\
\text { writings }\end{array}$ & 72 & 72 \\
\end{tabular}

It is shown in the data that the performances of the students in both pairs of methods compared were not significantly different. Although the performances of the students were not significant difference, it was found that the students performed better on the Entity method than on the Process. To conclude, the performances of the students if writing a composition with Entity method were not significantly different from their performances if writing a composition with Process. The insignificant difference in students' performances was attributed to their equal skills in writing compositions. Using no outline to write exposition of different methods showed identical results. An additional finding was that the two mean scores of the methods 
compared in were still in between the good to average score levels.

\section{The Difference of Students' Essay Writing Quality with and without Using Outline}

This part is to look at whether there was any significant difference of essay writing quality by using an outline and without using outline or not. The significance of means was tested using one-way ANOVA and Tukey Ttest. The mean scores of the two writing strategies were also presented to complete the discussion.

The result of one-way ANOVA showed significant difference between using an outline and without using an outline on the idea development quality of students' composition. The means for composition using an outline was significantly different from the mean for composition without using an outline. The $\mathrm{p}$ value which was 0.000 was smaller than the level of probability $(\mathrm{p}<0.05)$ gave the evidence of it. Similarly, Tukey's test for a pair wise comparison between outlining and nonoutlining (levels of writing strategy) showed the p-value that was 0.0002 was also smaller than the 0.05 level of probability. This shows that the there was a significant difference in means between outlining and non-outlining. In addition, the statistical account for means showed that the means for composition writing using and not using an outline were significantly different, that is, 82.058 for outlining and 78.681 for non-outlining; the total mean for the outlining was greater than the mean for the non-outlining.

With the two statistical test findings and the print out of statistic for mean above, the study made a conclusion that the mean for essay writing using an outline was significantly different from the mean for that of without using an outline. The mean for outlining was very great compared to the mean for nonoutlining. This means that the idea development quality of students' essay if outlining was obviously better than that if without outlining.

It was clear from the data that there was a very great difference between outlining and non-outlining in means and it was proven that outlining was greater than non-outlining. The data proved considerably that using an outline to write essay gave positive results. This evidence signified that the students were already accustomed to use an outline if writing essay. It proved that writing strategy with outlining was an efficient and a successful strategy for essay writing. It was efficient since it could make the writing run smoothly as the result of already having the outline of ideas at hand, and was successful since it could help a writer successfully organize his ideas systematic and give focus on relevant materials as well as organize logical supporting details.

In relation to essay writing using an outline, it was found that the students have had an ability to write essay containing clear and well-organized ideas. They have got the skills to divide main ideas into topics and break them down further into most specific subtopics and divided the subtopics into other more specific subtopics. They have got the skills to express the ideas in high-quality language. The success of the students to write essay using an outline has proved how important an outline was for the production of a qualified piece of writing. This fact gave evidence to the statement of Goose (2001), Crème \& Lea (2003); Davis (2004); Donahue, 2007) \& Hayes (2011) who acknowledged the effect of using an outline and suggested writers to make one in order to produce qualified composition.

Writing an essay without using an outline, on the other hand, showed worse results compared to writing a composition using an outline. The mean scores for both writing strategies were significantly different. Although the difference was significant, the non-outlining mean score was still within the level of appropriateness. The mean score for essay without using an outline was obviously 
small compared to the mean score for using an outline, but that mean score itself was still in the average level of score category. Generally, it can be said that the outcome of this study, that is if the students used an outline, is not bad. This finding is in contrast to Langan's study (2008) dealing with a frame (outline) making and its relation to the writing of expository composition. Unlike the present study, his study came out with the findings showing low ability of the students to make an outline. However, the two studies showed a similarity in which the subjects of both studies who could write better outlines could also write better compositions.

Based on the results of this study and other related studies, there would be no doubt on the effects of using an outline to write essay. Outlining strategy proved to be better than the non-outlining strategy and even to some other strategies. Similarly, Duigu (2003) conducted studies on the use of writing strategies: listing, clustering, and outlining in writing essays and discovered that outlining strategy was good compared to listing and clustering strategies. Considering the positive effects of an outline, it is recommended to students in particular and writers in general to use an outline if writing. It has been proved statistically that outlining is a successful writing strategy.

There are some other reasons put forward might cause outlining one step ahead of nonoutlining. One of them is the outline itself. Outlining as a writing strategy functions as a blue print. It is a framework on which a composition to be based on. This condition makes students be focused on the materials of their writing. With a specified topic they can determine the content materials suitable for the topic. This idea is relevant to Duigu (2003) stating that an outline is an instrument that can make composition unified, well-ordered, and coherent. Further, he claimed that outlining shows the materials that are needed to develop the composition. It shows how the materials relate to one another and shows the parts of the whole.

Another reason is that an outline is a plan of a writing organization breaking a topic or a thesis into main units and subdivides the main units into subunits, and probably the subunits are further broken into small units. It is the skeleton of a composition; the structure around which the details and explanations are organized. These functions enabled the students to organize their ideas effectively and systematically. Besides, it allowed the students to run the writing smoothly since a defined outline of ideas was already made.

This study dealt with a constraint writing test in which students were given limited time to complete writing tasks or to write compositions. In such situation, the students got very limited time to think of the content materials to put in the writing. In addition, the students or people in general have a very limited capability in working memory. This situation and condition make the students need to make an outline for their composition writing. With a clear outline the students could express logically and systematically things perceived.

It is not easy for a writer to start writing without making a framework which is called an outline. How experienced one is, he still needs an outline to follow in order to produce a qualified piece of writing - a writing containing clear and well-organized ideas and expressed in high-quality language (Creme and Lea, 2003). This statement was strengthened by the findings of the study in which the students were able to write composition better if using an outline.

Based on the evidence above, it can be concluded that the idea development quality of students' composition if using an outline is significantly different from the quality of composition without using an outline. The outlining composition quality obviously proved to go beyond the non-outlining quality. One definite reason making outlining better 
than non-outlining in the context of composition quality was that an outline is a writing plan dealing with structured and systematic organization of writing materials. The outline made the students focused on the materials of the writing. It reminded the students of the thesis statement and the controlling ideas, the supporting details, and the conclusion words that they put in their writing. These functions of an outline were suspected to be the sole cause of outlining being better than non-outlining.

\section{CONCLUSION AND SUGGESSTIONS}

Considering the problems, the objectives and the findings of the study, conclusion is drawn as follows:

1. There was a significant difference between using and not using an outline on the idea development quality of students' essay.

2. The means of the two paired-methods compared (Entity and Process with Outlining) were insignificant difference.

3. The two paired-methods compared (Entity and Process without Outlining) showed insignificant difference in means.

It is suggested, therefore, to use outlining strategy as a very important pre-writing aspect before students start to write an essay. In addition, more extensive research on other aspects of essay writing is needed to be conducted in order to have comprehensive overview of students' quality in essay writing.

\section{REFERENCES}

Ayam, Jean. 2010. Research Writing and

Presentation Pattern Paper presented at the SIG Writing Conference, September $8^{\text {th }}$ $10^{\text {th }} 2010$, Heidelberg, Germany.

Braaksma, Martine, Rijlaarsdam, Gert \& Berg, Huub Van Den. 2010. Hypertext Writing Versus Linear Writing: Effects on Pause Locations and Production Activities and Its Relation With Text Quality. Paper presented at the SIG Writing Conference,
September $8^{\text {th }}-10^{\text {th }} \quad 2010, \quad$ Heidelberg, Germany.

Crème, Phyllis \& Lea, Mary. 2003. Writing at University. Second Edition. Philadelphia: Open University Press.

Darus, Saadiyah \& Subramaniam, Kaladevi. 2009. Error Analysis of the Written English Essays of Secondary School Students in Malaysia: A Case Study. European Journal of Social Sciences, 8(03), 483-495.

Davis, Kenneth. 2004. Manage Your Writing. California: Komei Inc.

Donahue, Steven. 2007. Writing: Road-Runner English. Indianapolis: MacGraw-Hill Inc.

Duigu, Gaby. 2003. Essay Writing for English Test. Sydney: Academic English Press.

Gay, Lorrie R, Mills, Geoffrey E, \& Airasian,Peter W. 2011. Educational Research: Competencies for Analysis and Applications. $10^{\text {th }}$ Edition. California: Prentice Hall.

Goose, Allen. 2001. Eight Kinds of Writing: Lesson and Practice for Writing Tests. Second Edition. Portland: Weston Walch Publisher.

Hayes, John. 2011. Kinds of Knowledge Telling: Modeling Early Write Development. Journal of Writing Research, 03(02), 366-384.

Langan, John. 2008. College Writing Skills. Sydney: McGraw-Hill Press.

Leitjen, Marielle, Et Al. 2011. Coordinating Sentence Composition With Error Correction: A Multilevel Analysis. Journal of Writing Research. Vol. 02 No. 03. Pp. 331-363

Piolat, Anni \& Frutttero, Laurant. 2011. Effects Of Memory Span on Cognitive Load and On Writing Strategies. Journal Of Writing Research, 03(2), 366-384.

Sulistyo, Gunadi, H. 2008. English as A Measurement Standard in The National Examination: Some Grassroots' Voice. LINGUA: Journal Ilmu Bahasa dan Sastra, 3(2), 35-39. 
Salija, The Effect of Using Outlines on Idea Development Quality...

Torrance, Mark. 2011. Learning to Write Effectively: Current Trend in European
Research. Nottingham: Nottingham Trent University Press 